\title{
Choice of Engineering Education among Girls in India - The Journey
} so far

\author{
Geethalakshmi PM ${ }^{1}$, Sumam David S ${ }^{2}$, Vinod V. Thomas ${ }^{3}$ \\ ${ }^{1}$ Research Scholar, Department of Humanities \& Management, MIT, MAHE Manipal, Karnataka \\ ${ }^{2}$ Professor, Department of E\&C, NITK Surathkal, Karnataka \\ ${ }^{3}$ Professor, Department of E\&E, MIT, MAHE Manipal, Karnataka \\ 1 geetha.pm@manipal.edu \\ ${ }^{2}$ sumam@ieee.org \\ ${ }^{3}$ vinod.thomas@manipal.edu
}

\begin{abstract}
Gender disparity in engineering enrolment is quite significant although there is only a very narrow gap in girls' enrollment in higher education in India. The overall enrolment of girls in engineering programs is $27.5 \%$. By affirmative action of introducing supernumerary quota for girls, Ministry of Education targets to increase the enrolment of girls which was $8 \%$ and $14 \%$ respectively in IITs and NITs in $2016-17$ to $20 \%$ in 2020-21. Therefore, it is essential to explore the reasons behind the reluctance of girls in choosing engineering education, even when the nature of engineering jobs has evolved to be gender neutral. It is even more significant now when National Education Policy (NEP) 2020 is targeting to achieve a Gross Enrolment Ratio (GER) of $50 \%$ by 2035 from the current $27 \%$. This paper reviews the existing studies to understand the nature of influence of both external and internal factors and their interaction on the girls' choice of higher education. Literature review of the research articles for two decades was conducted. It includes both published and unpublished work on the subject. There are no studies conducted nationwide, post 2004 to address the reasons for disproportionate representation of girls in engineering education in India. It is found that the findings are contextual in nature with respect to culture of the society. In, particular, the influence of parental perception influences the association of gender with engineering studies, among the girls. Awareness and exposure of the nature of engineering jobs among parents and the girls can bring in the desired change.
\end{abstract}

Keywords: Enrolment in Engineering, gender disparity, higher education, self-perception, Identity

\section{Corresponding Author}

Geethalakshmi P. M., Department of Humanities \& Management, Manipal Institute of Technology, MAHE, Manipal-576104, geetha.pm@manipal.edu

\section{Background}

Gender disparity in engineering enrolment is quite significant although there is only a very narrow gap in girls' enrollment in higher education in India as shown in Fig. 1. The preference, as exercised by girls, finds engineering as the last choice as compared to other professional courses like Medicine, Science and Commerce (All India Survey on
Higher Education (AISHE) reports-2013-2019). Figure 2 depicts the overall enrolment of girls in various programs and the dotted line indicates the trend in enrolment for engineering programs.

By affirmative action of introducing supernumerary quota for girls, Ministry of Education targets to increase the enrolment of girls which was $8 \%$ and $14 \%$ respectively in IITs and NITs in $2016-17$ to $20 \%$ in $2020-21$. Therefore, it is essential to explore the reasons behind the reluctance of girls in choosing engineering education, even when the nature of engineering jobs has evolved to be gender neutral. It is even more significant now when NEP 2020 is targeting to achieve a GER of $50 \%$ by 2035 from the current $27 \%$. Year on year analysis reveals that, while the number of women opting for higher education has steadily increased, the number opting for engineering has not increased. Also, the number of women opting for Science education has increased while engineering enrolment remains almost constant.

\section{Purpose}

Reluctance in choice of engineering education among girls is not in alignment with nation's policy of gender equality. To be competent in the global market, technology is the key (Woetzel, 2015). It is also important to understand why half of the population is turning away from the prospective careers. Wall, K (UNESCO report, 2010) highlights the need of solving societal problems through technology. 


\section{Method}

Research work undertaken during last two decades (20002019), in Indian as well as non-Indian context are reviewed to understand the present position. The literature consists of reports at international and national level by various forums, research articles and literature reviews. It may be noted that much of the work is done in choosing Science, Technology, Engineering and Mathematics (STEM) fields together.

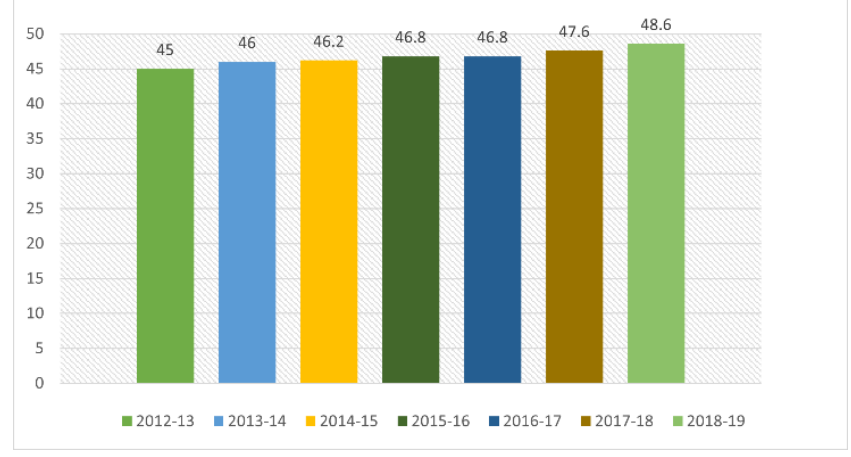

Fig. 1 Percentage of female enrolment in higher education based on AISHE reports

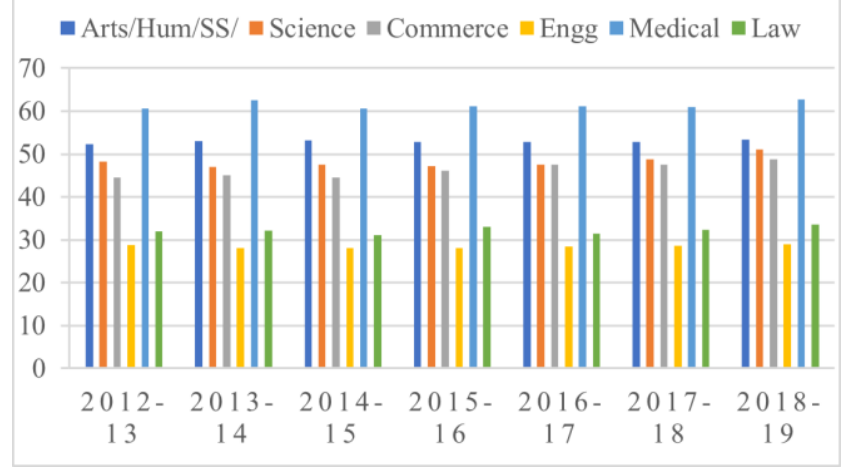

Fig. 2 Percentage of female enrolment trend discipline-wise based on AISHE reports

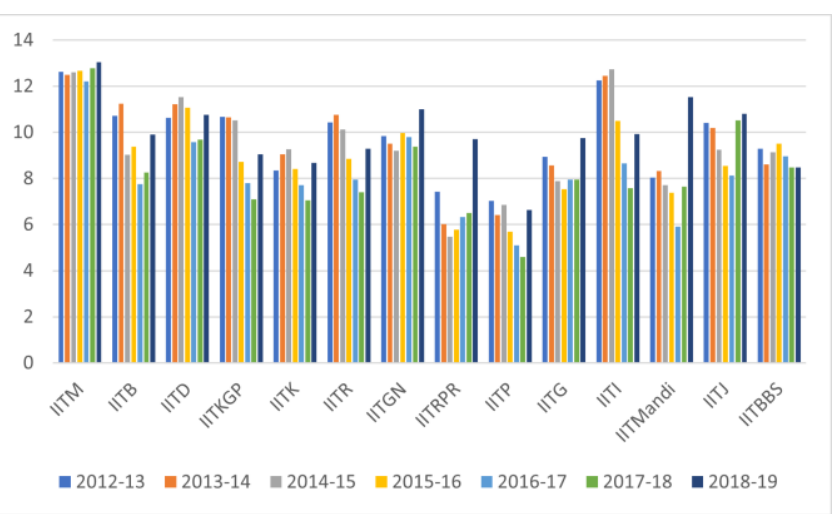

Fig. 3 Percentage of female enrolment in IITs based on NIRF data

\section{Literature Review}

A. Engineering as a Choice of Education (Career)-Current Scenario

Countries aiming to have sustainable growth, need to have their people possess technical skills. This awareness has resulted in continued efforts of countries in reducing the gender gap in science and technology (UNESCO, 2010).

An examination and study of seven Asian countries, namely Cambodia, Indonesia, Malaysia, Mongolia, Nepal, Republic of Korea and Vietnam, reveals enrolment of girls in science ranging from $48 \%$ in Malaysia to $13 \%$ in Cambodia (Salmon, 2015).

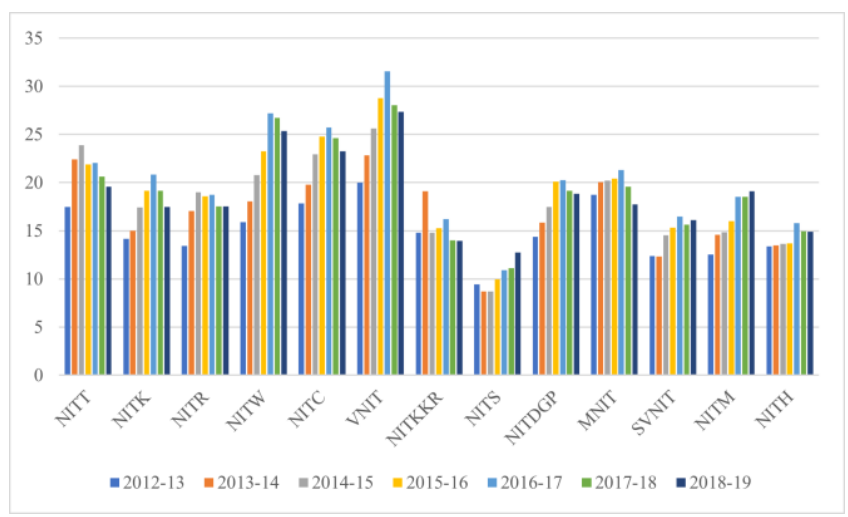

Fig. 4 Percentage of female enrolment in NITs based on NIRF data

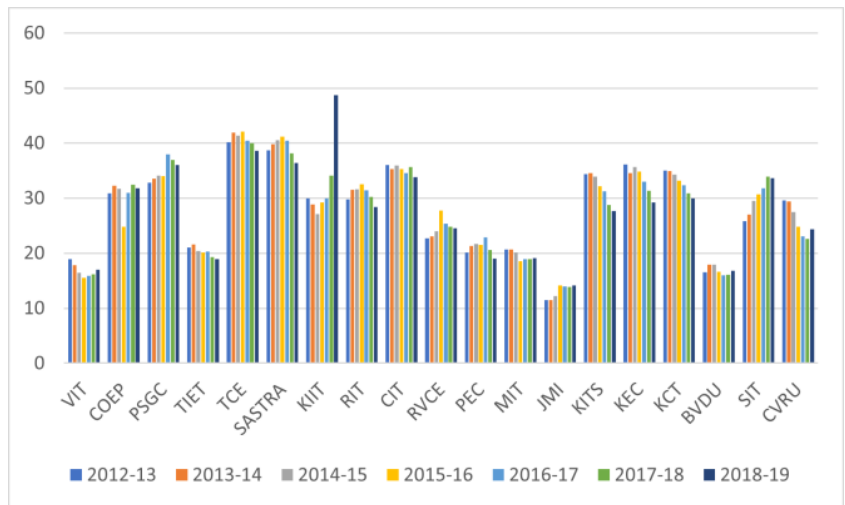

Fig. 5 Percentage of female enrolment in other (Non-IIT \& Non-NIT) institutes based on NIRF data

As per UNESCO report (Chavatzia, T., 2017), the global average of female enrolment in engineering education is $27 \%$ (considering 115 countries and their dependent territories). It was found that significantly less portion of girl students enroll into engineering studies, even when they take up Science stream. Comparatively higher female enrolment is seen in South-East Asia, Arab states and some European countries, while lower enrolment is witnessed in North America, sub-Saharan Africa and Europe.

Programme for International Student Assessment (PISA), conducted for members of Organization for Economic Cooperation and Development countries (OECD, 2015) found that $39 \%$ of the high performers among girls wanted a career in science. However, the interest in science translated 
to health-related career rather than engineering for girls. India will be part of PISA from 2021 onwards.

India, has been making efforts to bridge the gender gap in technology education. Enrolment data of the top hundred colleges, as per National Institute Ranking Framework (NIRF) was studied for the period 2012 to 2019. The results are shown in Fig.3, Fig. 4 and Fig. 5 representing enrollment in IITs. NITs and other colleges respectively. The average enrolment of girls is $9.13 \%$ in IITs and $18.17 \%$ in NITs and $27.95 \%$ in other colleges, as against national average of $27.5 \%$ (AISHE survey, 2019). It may be observed that India is in a5 better position compared to North American and European countries. Supernumerary quota for women was introduced for undergraduate programs in IITs and NITs from 2018-19 admissions. In the first year of implementation, 2018-19, $14 \%$ of seats were added, going up to $17 \%$ in 2019-20 and $20 \%$ in 2020-21. The government's aim is to ultimately reserve $20 \%$ of seats for women. During 2013 and 2014 NIT admissions, weightage was given to Class 12 marks and a significant increase was observed in the number of girls admitted in many of the NITs. A higher average can be seen in some of the other colleges; KIIT Bhubaneswar has 30\% reservation for girls and engineering admissions of colleges under Anna University, Tamil Nadu is based only Class 12 marks.

B. Engineering as a Choice of Education (Career) Significant Reviews

Dasgupta and Stout (2014) segregated factors influencing girls at three stages of life - namely, childhood \& adolescence, emerging adulthood and young to middle adulthood. The review attributed the underrepresentation to gender stereotyping, parents influence, peer influence in schools, lack of female role models, gender bias in hiring policies, organization culture and work-life balance.

Ceci et al. (2014) reviewed literature from the lens of goal congruence to see the impact of community orientation in choosing mathematics intensive science fields as compared to non-math intensive science fields. Their findings mark a departure from the other findings as they declare that there are no evidences of salary discrimination, gender bias during grant and fund consideration, no chilly climate experienced by girls in educational institutes. They also suggest that henceforth, researchers should not focus on historical barriers but should focus on pre-college barriers.

Diekman et al. (2017) used the goal congruence theory to understand and analyze the persistence of STEM career among women. The review, through the lens of communal goal processes, explains various stages of women (girls), during which, it affects their motivation to pursue STEM fields. The association of STEM field with community oriented welfare is the central theme. In addition, the impact of self-efficacy on the choice of STEM field is emphasized. It is also noteworthy that the review acknowledges that there is no influence of gender in one being proficient in mathematics - neither in the capability nor in the intention to pursue. The authors suggest that the future studies should focus on considering the individual differences and difference in culture while examining the communal goal preference. The authors also suggest that the combined effect of both agentic motives and communal motives needs to be examined leading to STEM preference.

Venkatesh, S (2015) examines the literature on women in science and constantly compares developed countries with developing countries with respect to state of science and technology. Significant findings are that while women face systematic discrimination in the developed countries having been perceived to have lower cognitive and reasoning abilities, Indian women do not face such kind of gender discrimination. They are respected for their cognitive capabilities which is demonstrated by equal opportunities, absence of chilly climate in the educational institutes and organizations. Balancing dual role is the main reason quoted for not moving up the ladder in career. On the contrary, family support is the major factor in pursuing higher education or career of their choice. The review also finds that married women are more successful in negotiating the career than single ones. Thus, this study opens up new arena of study in the Indian context. Further, literature focusing on the influence of individual factors on women under representation in STEM were studied and they are broadly categorized as Contextual and Personal. Personal refers to all the factors that are unique to individual, such as identity, capability, interest etc. The factors that are external to the individual which also influence the decision are termed Contextual for example - family, society, school etc.

\section{Personal factors}

A combined effort (Salmon, 2015) on studying the representation of women in engineering by Korea and UNESCO in seven of the Asian countries, attributed the reasons for under representation to mainly lack of female role models, inequality in accessing education, lack of motivation and aspiration among girls. Interestingly, the study found that girls favour science subjects such as biology and pharmacy as opposed to physics and computer science. The seven countries studied are Cambodia, Indonesia, Malaysia, Mongolia, Nepal, the South Korea and Vietnam.

Schmidt (2011) reviewed a large sample (216,032 male and 41,646 female) of applicants to the U.S. Air Force, and concluded that women demonstrate lack of or lesser interest in technical subjects as compared to non-technical subjects. Therefore, it is said that one's ability is dependent on one's interest and attributes the lack of interest to lack of exposure. A meta quantitative analysis (Nye et al., 2012) of 60 years of literature on interest, congruence and performance revealed that interests are significantly influencing the performance and, individual interest should match the organization interest (congruence) for enhanced performance. This information is useful in understanding the outcome of the work by Schmidt (2011).

Maltese et al. (2017) explored the reasons behind interest in STEM and persistence in STEM field among male and female using a large sample size $(\mathrm{N}=8000)$ which included students and working population. The responses were elicited through survey. Major findings are that female seek support externally to pursue their STEM education and career and that the interests change, either internally or 
externally. Therefore, to judge any student based on their childhood interests may not be valid.

A study of 56 women engineers, belonging to Australian university, by Mary et al. (2013) revealed that women who continued to stay in the field despite all the challenges, attributed their success to belief in self as engineer.

A study (Kulturel-Konak, S. et al., 2011) involving 313 students (both STEM \& non-STEM) of Penn university, USA analyzed difference in learning styles of male and female and their association with technical education. It was found that the teaching techniques adopted in technical institutes favour males than females with respect to their learning styles.

A longitudinal (10-year gap) study (Eccles \& Wang, 2016) of US high school students tested the association of Selfconcept on mathematics and verbal capability with choice of STEM or non-STEM career. The salient findings of the study were that it was neither mathematics nor verbal capability but the values they hold and the perception which career will align with their value system, decides the career. This was true for both the genders. The study, however, also found that women gave more value to family as compared to men in deciding the career.

A cross sectional study of high school students by Makarova et al. (2019) found that both girls and boys (1364 Swiss secondary school students; quantitative survey) perceive mathematics, physics and chemistry as masculine in nature. The study suggests that this has a bearing on the career aspirations of girls.

The combined effect of perceived competence, interest, recognition and identity culminating in the choice of engineering career was carried out by Godwin et al. (2016). The study, thus, highlights the significance of supporting girls in developing the interest and identity by means of communicating the welfare-nature of engineering.

Wehrwein et al. (2007), in their study found that there exists significant difference in learning style preference among female and male learners. While female learners predominantly prefer Kinesthetic mode, male prefer multiple mode.

Male et al. (2009), in their study involving 300 engineers concludes that successful execution of any engineering job requires female competencies. It is, however, interesting to observe that all the non-technical competencies were classified as female!

A national longitudinal study (Wang et al., 2013) consisting of 1490 participants with respect to mathematics ability and verbal ability was carried out. The responses were elicited from the participants when they were in $12^{\text {th }}$ and when they were 33 years old. The significant finding was that people who possessed both high mathematics and verbal ability were more likely to perceive non-STEM careers than those who had high mathematics but moderate verbal ability. Interestingly, it was found that it was more of women who had both high mathematics and high verbal ability, suggesting that it was availability of more choices that influences career than the lack of ability. This also questions the measures taken by the policy makers and the society to encourage girls / women take up STEM field. Are they limiting their dreams?

A study (Smeding, 2012) of French women engineers in comparison to male engineers and female humanities students, found that women engineers held weaker implicit association of gender stereotypes and hence their performance in mathematics remained high.

Diekman et al. (2010) in their study of students from both psychology and STEM, found that women tend to see STEM career as impediment to community oriented activities and choose to opt out of STEM career.

The nuances of gendered identities of engineering were explained through the term real engineering and nuts and bolts by Faulkner (2007). The author observes that since the execution belongs to blue collared workers who predominantly are male, engineering assumes the masculine identity. Therefore, any other social interaction, leadership skills, people skills are given feminine identity. It is interesting to note that the desire for identity even overtakes their desire for career progression. The conflicts between the technical and the managerial teams are true for all the industries be it aircrafts or technical education.

A longitudinal study (Hirschi, 2011) of 325 Swiss students found correlation between higher levels of career choice readiness with higher self-esteem, self-efficacy and fewer perceived barriers and increase in readiness with time.

D. Contextual factors

1) Parents \& families: A qualitative research of 28 engineers, across Asian countries revealed how families perceive engineering career for girls - it was on both extremes - as a prestigious career on one end and as dirty and dangerous job on the other end. The major themes which emerged in the analysis were - engineering as unsuitable, engineering as masculine, engineering as hindrance to marriage, family's unconditional support, family as resource provider (Dutta, 2017). The work brought out importance of influence of culture, which makes it possible for girls to pursue engineering but with caution of maintaining the expectations or norms of the family intact. The interplay of supporting and countering factors, ultimately leading to women pursue engineering leads to a question unexplored-what made it possible for all the above girls pursue and stay in engineering fields.

2) A study (Gautam, 2015) of 72 master graduates who were science and social science students attributed the choice of career by women as influenced by father. The subjects chosen in the $11^{\text {th }}$ class, were largely guided by proximity to the college, availability of hostels, financial status of the family and safety concerns, rather than what one wanted to pursue. However, the participants said that the final decision was their own and they take responsibility for their choice of subject. The study also throws light on the gendered perception of people on the choice of career.

Bakshi, et al. (2012) in their study of 65 youth from Mumbai with respect to career choices, found that most of the women in the group decided their career on their own, while most of the men had the influence of their father. The inference was that the career of women was not given due consideration. 
Another notable finding was that only one woman wanted to be engineer as against 8 among men. Women were more in number in careers that required creativity and commerce. All the education related career was chosen by only women. The work triggers a question as to whether the findings are contextual with respect to the region and the community. The culture of Mumbai necessitates one to find a career which one is interested in, else it might induce stress.

DeWitt and Archer (2015), in their two cross-sectional studies of the students $(\mathrm{N}=9300)$, who were in the last year of their primary school and those (4600) who were in their third year of secondary school, attributed the conversion of science aspiration to career to the science capital (parents' /family's science acquisitions; for example, parents holding engineering degree).

Archer et al. (2013), attributed the lack of interest shown by 10-14 year-old girls to the notion they and their parents hold about the science careers, which do not match with their identification of being feminine. The findings are based on 5 -year longitudinal study and are based on survey response $(\mathrm{N}=9000)$ and interviews with girls $(\mathrm{N}=92)$ and their parents $(\mathrm{N}=78)$. Largely, their perception is that science careers are considered to be not girly, it's for geeks and therefore it does not fit into their frame of appropriate career for girls.

Ertl et al. (2017), found in their study of 296 women from different German universities, where women representation was less than $30 \%$, that women succumb to the stereotype created by the parents, family and the school. This resulted in reduced self-concept of the girls, even though they had good grades in STEM subjects. This was mainly due to not giving credit to their intelligence but to their diligence. It was also found that girls perform better when the support from parents is indirect rather than direct.

3) Society \& Organizations: A comparative study (Langen et. al, 2005) of four western countries namely, Sweden, Netherlands, USA and UK, examined the implications of the state policy and the influence of society, accessibility (to STEM education), and affordability to life-style requirements, on women representation in science and technology fields. Interestingly, it was found that, within western countries, there are differences along with the similarities on what contributes and hinders women representation in science and technology fields. The significant differences were implementation of women inclusive policies and influence of family requirements. For example, non-availability of family friendly policies like paid maternity leave resulted in women choosing part-time jobs, which meant non-STEM jobs. Similarly, in USA, women working is out of compulsion to meet the high standard of living. Friendly education policies of Sweden have resulted in more number of people choosing the STEM career. Broadly, it was understood that the categories responsible for STEM education or career were quality (or lack of) of education, encouraging pay and perks for STEM jobs, beliefs that STEM is difficult, inaccessible and for men and the government policies.

Association of Academies and Societies of Sciences in Asia (AASSA 2015) compared ten countries with respect to women under representation in science and technology. The data pertaining to enrolment and employment based on the reports sent by the countries were discussed. The study attributes the reason to culture of the Asian societies where women have dual responsibilities and to ineffective implementation of government policies in all the countries. The report, however, does not throw light on what makes it possible for women to pursue career like medicine, which are more challenging with respect to work-life balance.

Two extensive studies by Parikh et al. (2003) throw light on perceptions and experience of both the sides, that is the women engineers and the employers. The study highlights the increase in enrolment of girls into engineering however warns on the increase of unemployment. The study analyses the career profile and opportunities for women engineers and listens to the responses from the employers. The factors touched upon were the mindset of the society, family and the organizations. Interestingly, perceptions of women engineers were contradicting from how their men counterparts saw them. The situation, preferences and the mindset of all the players has changed over a period of 15 years. therefore, to understand the dynamics behind lack of girl enrolment in engineering a new study is warranted.

Kurup \& Maithreyi (2011) in their study of 568 women scientists of India (including those who were not working), argued that it is the organizational factors that significantly hinder the women retention in science rather than family commitments and gender notions, as popularly believed. They stated that organizational practices such as flexible working hours go long way in facilitating women scientists' growth.

Shakya \& Meenakshi (2013) found in their study that the career preference of the youth was influenced by sociocultural context in which they live. Significant contribution of this study was that they recorded the change in preference of the choice over a period of six months. Further analysis of the results revealed that the career choices are not absolute but vary as they gain more and more knowledge about the choices available and their performance in the subjects. Therefore, major influence was self-awareness. Another important finding of the study was that the most preferred option was science \& technology amongst both girls and boys, hence contributing to the contradictory evidence that there was no influence of gender on career choices.

Nation-wide data was collected from women engineers of 30 US engineering universities. A qualitative analysis (Fouad, et, al., 2017) of the statements by women engineers who quit after working for some years revealed that when there is mismatch between their occupational values such as comfort, altruism, safety, achievement needs and autonomy with respect to what organization working environment reinforces, they quit. It also proves that there was no problem with women engineers' capability, potential or interest in technical subjects.

Torre et al. (2018), studied the reasons behind women under representation in six schools in Barcelona, Spain $(\mathrm{N}=1060)$. The study attributed the reasons mainly to the immediate environment and the stereotypes held by the society and to a lesser extent, women being not interested in engineering. 
Stoet \& Geary (2018) used an international database $(\mathrm{N}=472242)$ to analyze the relationship between selfefficacy, actual performance and the gender equality to explain the gender gap in STEM subjects. Significant findings were that gender gap was relatively more in more gender equal countries; when not subjected to pressure of economically performing well, women choose to pursue where their strength lies. It was found that comparative strength of girls was more in reading and comprehension visà-vis science and mathematics.

Stout et al. (2016) studied the perceived notion of women and men students about STEM and non-STEM careers to be agentic or community oriented leading to their respective choice. Significant finding was that when women who perceived STEM education, did so because they believed it as community-oriented and men who pursued behavioral sciences did so because they believed it to be agentic in nature.

Mlambo \& Mabokela, (2017) in their work found that, women engineers who continued in academia, did so as they experienced support from the peers, flexibility in working and absence of gender discrimination. The participants were comparing their experience in industry in arriving at these conclusions.

Miller et al. (2015) carried out correlational study to compare data of 66 nations (secondary data) to understand how people bring gender in science either by explicit or implicit association of Gender to engineering.

Subramanian (2007) studied men and women in Indian research institutes and found that there was systematic denial of merit of women scientists. On the surface it appeared as equal opportunity.

Cheryan et al. (2013) found that girl students held stereotype picture of computer engineers as nerd, intelligent, not attractive, lacks interpersonal skills and that this stereotype was influenced by the media.

Stout, J. G et al. (2011) conducted two cross-sectional and one longitudinal study to see the effect of female role models in the STEM fields on the stereotype perception of girl students. The study highlighted the significance of exposure to female role models in strengthening the performance and participation in STEM subjects.

Morganson V. J et al. (2010), discussed the significance of social coping on women persisting in STEM field. A comparative study of women and men revealed that women rate social coping more positive with respect to commitment in STEM field and intention to turn over as compared to men. It was found that women associate social coping to academics lesser as compared to men.

Gupta N (2019), in her article elaborates the schemes (2003 to 2017) for Indian scientists by the Government of India. The reason for not utilizing these schemes effectively is attributed to the societal culture and family system. This contradicts the findings of earlier research by Kurup et al., (2011)

4) Influence of schools: A comparative study (Escueta, M., et, al., 2013) of the Indian scenario with the US scenario revealed that there is conducive atmosphere in the Indian schools and colleges for girls; there is no explicit or implicit bias felt by the girls discouraging them to pursue engineering studies. Secondly, women experienced respect and remain confident and motivated in engineering fields than nonengineering fields in India. The last point, which needs further exploration is the criteria of selection in premier Indian colleges which systematically discourages women entry into engineering fields. An internal study carried out at IIT, Mumbai found that there is no correlation between the JEE score and the performance of the students at IIT, whereas, there is correlation between the $10^{\text {th }}$ and $12^{\text {th }}$ performance and the CGPA at IIT. The modifications to the JEE content and the elimination of screening test, has however not resulted in significant increase in the enrolment (NIRF, 2019). In, MIT, US, modifying the entrance to test to make it more holistic has resulted in increased enrolment of girls.

Indian Express Survey (2018) published the findings that in India, equal weightage is given to Engineering and Medical education $(23 \%)$ and that the parents and schools support in making the career decision. There is no mention of gender discrimination in the study.

Women tend to depend on all possible resources prior to taking a decision of joining engineering education. In comparison to men, they ensure confirmation from parents and the society to ensure an informed decision (Mahajan \& Golahit, 2017). Interestingly, the portion of self-reliance was same for both men and women.

Oliver M. C et al. (2017) in their qualitative study of high school students found that students identified school as the highest influencing factor in their choice of STEM education. Here, the practices at the school demonstrated culture that encouraged competitiveness, opportunity provided and academic focus.

\section{Results}

Most of the work focuses on either personal or contextual factors. However, career aspirations and hence the choice of education was seen as the consequence of constant interplay between personal and contextual factors. On the personal front, capability, interest and identity shape the choice of education and career, get significantly influenced by the parents' perception of gender as well as the social identity. Self-perception with respect to capability and identity also plays significant role in the choice of engineering education among girls. In Indian scenario, little work has been done post 2003, on national level.

\section{Conclusions}

Since, the issue needs to be addressed at different levels, holistic studies are warranted. The changing nature of engineering needs to be communicated to all the key stakeholders. Awareness and exposure of the nature of engineering jobs among parents and the girls can bring in the desired change. Since the studies reveal that in Indian context, girls do not experience gender discrimination in schools and colleges, we recommend that future studies be done to understand the influence of academic interest, learning experiences, self- efficacy given that contextual 
factors like school atmosphere and society gives uniform exposure to all.

\section{References}

Annual Reports (2013, 2014, 2015, 2016, 2017, 2018, 2019) All India Survey on Higher Education.

Bakshi, A. J., Gandhi, H. N., Shah, R., \& Maru, K. (2012) Influences on career choices as perceived by youth in Mumbai. Indian Journal of Career and Livelihood Planning, 1(1), 7-18.

Chavatzia, T. (2017) Cracking the code: Girls' and women's education in science, technology, engineering and mathematics (STEM).

Ceci, S. J., Ginther, D. K., Kahn, S., \& Williams, W. M. (2014) Women in academic science: A changing landscape. Psychological Science in the Public Interest, 15(3), 75-141.

Cheryan, S., Plaut, V. C., Handron, C., \& Hudson, L. (2013) The stereotypical computer scientist: Gendered media representations as a barrier to inclusion for women. Sex roles, 69(1-2), 58-71.

Dasgupta, N., \& Stout, J. G. (2014) Girls and women in science, technology, engineering, and mathematics: STEMing the tide and broadening participation in STEM careers. Policy Insights from the Behavioral and Brain Sciences, 1(1), 21-29.

Debalina Dutta (2017) Cultural Barriers and Familial Resources for Negotiation of Engineering Careers Among Young Women: Relational Dialectics Theory in an Asian Perspective, Journal of Family Communication, 17:4, 338355.

Diekman, A. B., Brown, E. R., Johnston, A. M., \& Clark, E. K. (2010) Seeking congruity between goals and roles: A new look at why women opt out of science, technology, engineering, and mathematics careers. Psychological Science, 21(8), 1051-1057.

Diekman, A. B., Steinberg, M., Brown, E. R., Belanger, A. L., \& Clark, E. K. (2017) A goal congruity model of role entry, engagement, and exit: Understanding communal goal processes in STEM gender gaps. Personality and Social Psychology Review, 21(2), 142-175.

Eccles, J. S., \& Wang, M. T. (2016) What motivates females and males to pursue careers in mathematics and science? International Journal of Behavioral Development, 40(2), 100-106.

Ertl B, Luttenberger S and Paechter M (2017) The Impact of Gender Stereotypes on the Self-Concept of Female Students in STEM Subjects with an Under-Representation of Females. Front. Psychol. 8:703.

Escueta, M., Saxena, T., \& Aggarwal, V. (2013) Women in Engineering: A comparative study of barriers across Nations. Aspiring Minds. Retrieved March, 2, 2015.

Faulkner, W. (2007) Nuts and Bolts and People' GenderTroubled Engineering Identities. Social studies of science, 37(3), 331-356.
Fouad, N. A., Chang, W. H., Wan, M., \& Singh, R. (2017) Women's reasons for leaving the engineering field. Frontiers in psychology, 8, 875 .

Gautam, M. (2015) Gender, Subject Choice and Higher Education in India: Exploring 'Choices' and 'Constraints' of Women Students. Contemporary Education Dialogue, 12(1), 31-58.

Godwin, A., Potvin, G., Hazari, Z., \& Lock, R. (2016) Identity, critical agency, and engineering: An affective model for predicting engineering as a career choice. Journal of Engineering Education, 105(2), 312-340.

Gupta, N. (2019) Analysing gender gap in science: Government of India initiatives. Current Science, 116(11), 1797.

Hirschi, A. (2011) Career-choice readiness in adolescence: Developmental trajectories and individual differences. Journal of Vocational Behavior, 79(2), 340-348.

Indian Express survey, (2018) Retrieved from https://indianexpress.com/article/education/indian-studentstake-more-extra-classes-than-other-countries-survey/

Jennifer DeWitt \& Louise Archer (2015) Who Aspires to a Science Career? A comparison of survey responses from primary and secondary school students, International Journal of Science Education, 37:13, 2170-2192.

Kulturel-Konak, S., D'Allegro, M. L., \& Dickinson, S. (2011) Review of gender differences in learning styles: Suggestions for stem education. Contemporary Issues in Education Research, 4(3), 9-18.

Kurup, A., \& Maithreyi, R. (2011) Beyond family and societal attitudes to retain women in science. Current Science, 43-48.

Langen, A. V., \& Dekkers, H. (2005) Cross-national differences in participating in tertiary science, technology, engineering and mathematics education. Comparative Education, 41(3), 329-350.

Louise Archer, Jennifer DeWitt, Jonathan Osborne, Justin Dillon, Beatrice Willis \& Billy Wong (2013) 'Not girly, not sexy, not glamorous': primary school girls' and parents' constructions of science aspirations. Pedagogy, Culture \& Society, 21:1,171-194.

Mahajan, P., \& Suresh, G. (2017) Engineering a woman: Marketing opportunities and challenges in India. American Journal of Management Science and Engineering, 2(1), 1122.

Male, S. A., Bush, M. B., \& Murray, K. (2009) Think engineer, think male?. European journal of engineering education, 34(5), 455-464.

Maltese, A. V., \& Cooper, C. S. (2017) STEM Pathways: Do Men and Women Differ in Why They Enter and Exit?. AERA Open, 3(3), 2332858417727276.

Makarova, E., Aeschlimann, B., \& Herzog, W. (2019) The gender gap in STEM fields: The impact of the gender stereotype of math and science on secondary students' career aspirations. In Frontiers in Education (Vol. 4, p. 60). Frontiers. 
Mary Ayre, Julie Mills \& Judith Gill (2013) 'Yes, I do belong': the women who stay in engineering. Engineering Studies, 5:3, 216-232.

Miller, D. I., Eagly, A. H., \& Linn, M. C. (2015). Women's representation in science predicts national gender-science stereotypes: Evidence from 66 nations. Journal of Educational Psychology, 107(3), 631.

Mlambo, Y. A., \& Mabokela, R. O. (2017) 'It's more flexible': persistence of women engineers in the academy. European Journal of Engineering Education, 42(3), 271-285.

Morganson, V. J., Jones, M. P., \& Major, D. A. (2010) Understanding women's underrepresentation in science, technology, engineering, and mathematics: The role of social coping. The Career Development Quarterly, 59(2), 169-179.

National Institute of Ranking Framework (NIRF) reports, (2016-20) Retrieved from https://www.nirfindia.org/201619/EngineeringRanking.html

National Education Policy, (2020) Retrieved from https://www.mhrd.gov.in/sites/upload_files/mhrd/files/nep/ NEP_Final_English.pdf

Nye, C. D., Su, R., Rounds, J., \& Drasgow, F. (2012) Vocational interests and performance: A quantitative summary of over 60 years of research. Perspectives on Psychological Science, 7(4), 384-403.

OECD (2015) Education at a Glance 2015: OECD Indicators, OECD Publishing, Paris, https://doi.org/10.1787/ eag-2015-en

Oliver, M. C., Woods-McConney, A., Maor, D., \& McConney, A. (2017). Female senior secondary physics students' engagement in science: a qualitative study of constructive influences. International Journal of STEM Education, 4(1), 1-15.

Olmedo-Torre, N., Carracedo, F. S., Ballesteros, M. N. S., López, D., Perez-Poch, A., \& López-Beltrán, M. (2018) Do female motives for enrolling vary according to STEM profile? IEEE Transactions on Education, 61(4), 289-297.

Parikh, P. P., Bindu, R., \& Sukhatme, S. P. (2003). Job status and career profile of women engineers in India. International Journal of Engineering Education, 19(4), 631-638.

Salmon, A. (2015) A Complex Formula: Girls and Women in Science, Technology, Engineering and Mathematics in Asia. UNESCO Bangkok.

Schmidt, F. L. (2011). A theory of sex differences in technical aptitude and some supporting evidence. Perspectives on psychological science, 6(6), 560-573

Shakya, S., \& Singh, M. (2013) Career preferences among degree college adolescents in Kanpur City. Studies on Home and Community Science, 7(2), 95-98.

Smeding, A. (2012) Women in science, technology, engineering, and mathematics (STEM): An investigation of their implicit gender stereotypes and stereotypes' connectedness to math performance. Sex roles, 67(11-12), 617-629.
Stoet, G., \& Geary, D. C. (2018) The gender-equality paradox in science, technology, engineering, and mathematics education. Psychological science, 29(4), 581593.

Stout, J. G., Dasgupta, N., Hunsinger, M., \& McManus, M. A. (2011) STEMing the tide: using ingroup experts to inoculate women's self-concept in science, technology, engineering, and mathematics (STEM). Journal of personality and social psychology, 100(2), 255.

Stout, J. G., Grunberg, V. A., \& Ito, T. A. (2016). Gender roles and stereotypes about science careers help explain women and men's science pursuits. Sex Roles, 75(9-10), 490-499.

Subramanian, J. (2007) Perceiving and producing merit: gender and doing science in India. Indian Journal of Gender Studies, 14(2), 259-284.

Venkatesh, S. (2015) Forms of Social Asymmetry and Cultural Bias: Of Gender and Science in India and the World. Transcience (2015), 6(1).

Wall, K. (2010) Engineering: issues, challenges and opportunities for development. UNESCO

Wang, M. T., Eccles, J. S., \& Kenny, S. (2013) Not lack of ability but more choice: Individual and gender differences in choice of careers in science, technology, engineering, and mathematics. Psychological science, 24(5), 770-775.

Wehrwein, E. A., Lujan, H. L., \& DiCarlo, S. E. (2007) Gender differences in learning style preferences among undergraduate physiology students. Advances in physiology education, 31(2), 153-157.

Woetzel, J., Madgavkar, A., Gupta, R., Manyika, J., Ellingrud, K., Gupta, S., \& Krishnan, M. (2015) The power of parity: Advancing women's equality in India. Shanghai, Mumbai, San Francisco, Minneapolis, Gurgaon, Stamford: McKinsey Global Institute.

Women in science and technology in Asia - AASSA report, (2015) Retrieved from http://aassa.asia. 